DR NOLL CAMPBELL (Orcid ID : 0000-0002-8933-9339)

Article type : Original Research Article

\title{
Anticholinergics influence transition from normal cognition to mild cognitive impairment in older adults in primary care
}

Noll L. Campbell ${ }^{1,2,3}$; Kathleen A. Lane ${ }^{4}$; Sujuan Gao ${ }^{2,4}$; Malaz A. Boustani ${ }^{2,3,5}$; Fred Unverzagt ${ }^{6}$

\footnotetext{
${ }^{1}$ Purdue University College of Pharmacy, West Lafayette, IN;

${ }^{2}$ Indiana University Center for Aging Research, Regenstrief Institute, Inc. Indianapolis, IN;

${ }^{3}$ Sandra Eskenazi Center for Brain Care Innovation, Eskenazi Health, Indianapolis, IN

${ }^{4}$ Department of Biostatistics, Indiana University School of Medicine, Indianapolis, IN

${ }^{5}$ Department of Medicine, Indiana University School of Medicine, Indianapolis, IN

${ }^{6}$ Department of Psychiatry, Indiana University School of Medicine, Indianapolis, IN
}

Corresponding Author:

Noll Campbell

Regenstrief Institute, Inc

$1101 \mathrm{~W} .10^{\text {th }}$ Street

Indianapolis, IN 46202

campbenl@iupui.edu

Conflict of interest: The authors report no conflict of interests.

This is the author's manuscript of the article published in final edited form as:

Campbell, N. L., Lane, K. A., Gao, S., Boustani, M. A., \& Unverzagt, F. (n.d.). Anticholinergics influence transition from normal cognition to mild cognitive impairment in older adults in primary care.

Pharmacotherapy: The Journal of Human Pharmacology and Drug Therapy. https://doi.org/10.1002/phar.2106 
Funding: This work was supported by grants from the National Institute of Health: K23AG044440;

R01AG026096, R01AG09956, and P30AG10133. The content is solely the responsibility of the authors and does not necessarily represent the official views of the National Institutes of Health.

Key Words: Dementia, adverse drug reaction, primary care, anticholinergic, pharmacoepidemiology, modifiable risk factors, mild cognitive impairment

Meeting presentation: Presented at the Alzheimer's Association International Conference, London, England; July 16-20, 2017.

\section{Abstract:}

Study Objective: To determine the influence of anticholinergic medications on transitions in cognitive diagnosis of older adults in primary care.

Design: This observational cohort study was conducted over a mean follow-up of 3.2 years.

Anticholinergic exposure was defined by pharmacy dispensing and claims records. Cognitive diagnosis was performed by an expert panel at baseline and annually up to four years.

Data Source: Medication exposure and other clinical data were extracted from the Indiana Network for Patient Care (INPC), while the cognitive diagnosis was derived from a cognitive screening and diagnosis study.

Participants: Three hundred fifty adults aged 65 years and older without dementia and receiving primary care in a safety-net healthcare system.

This article is protected by copyright. All rights reserved. 
Measurement and Main Results: Cognitive diagnosis followed a two-phase screening and consensusbased neuropsychiatric examination to determine a baseline diagnosis as normal cognition, mild cognitive impairment $(\mathrm{MCl})$, or dementia, with a follow-up neuropsychiatric examination and consensusbased diagnosis repeated annually. The Anticholinergic Cognitive Burden scale was used to identify anticholinergics dispensed up to 10 years prior to enrollment and annually throughout the study. A total standard daily dose of anticholinergics was calculated by using pharmacy dispensing data from the INPC. Among 350 participants, a total of 978 diagnostic assessments were completed over a mean follow-up of 3.2 years. Compared with stable cognition, increasing use of strong anticholinergics calculated by total standard daily dose increased the odds of transition from normal cognition to $\mathrm{MCl}$ (odds ratio [OR] 1.15; 95\% confidence interval $[\mathrm{Cl}] 1.01-1.31 ; \mathrm{p}=0.0342)$. Compared with stable $\mathrm{MCl}$, strong anticholinergics did not influence the reversion of $\mathrm{MCl}$ to normal cognition (OR $0.95 ; 95 \% \mathrm{Cl} 0.86-1.05$; $p=0.3266)$.

Conclusion: De-prescribing interventions in older adults with normal cognition should test anticholinergics as potentially modifiable risk factors for cognitive impairment.

Medications with anticholinergic adverse effects are used by approximately $25 \%$ of older adults living in the community to manage symptoms such as incontinence, seasonal allergies, depression, and insomnia. ${ }^{1,2}$ Governing bodies such as the American Geriatrics Society and the Center for Medicare and Medicaid Services recommend against using these medications in older adults as the risks of peripheral and central adverse events outweigh the therapeutic benefits. ${ }^{3,4}$ Despite these recommendations, and availability of alternative treatments, population-based studies show no decrease in volume of prescription anticholinergic medications in older adults. ${ }^{5,6}$

This article is protected by copyright. All rights reserved. 
Cholinergic neurons are widely distributed throughout the basal forebrain with projections to the hippocampus, cortex, and medial temporal lobe, supporting learning, memory, organization, and attention. ${ }^{7,8}$ Anticholinergic drugs characteristically block cholinergic receptors, and have been shown in mouse models to increase beta-amyloid plaques and neurofibrillary tau proteins, hallmarks of Alzheimer's dementia (AD). ${ }^{9-17}$ Interruption of cholinergic neurotransmission has been correlated with cell death and memory deficits that mimic $A D .^{9,15,17}$ A recent study showed that anticholinergic users had smaller tissue volume in the cortex and temporal lobes, also correlating with worse performance in domains of memory, processing speed, and executive function compared with non-users. ${ }^{18}$

Several epidemiologic studies have identified the relationship between anticholinergic exposure and the diagnosis of cognitive impairment, including international studies conducted in the United Kingdom, France, Australia, and the United States. ${ }^{2,19-26}$ More recently, the quality of observational studies improved with the use of prescription records as a measure of medication exposure, as well as consensus-based diagnosis serving as the outcome. Two recent studies used pharmacy dispensing or claims data to show higher odds of cognitive impairment with increasing measures of anticholinergic exposure. $^{23,27}$

Prior work has predominantly shown relationships between anticholinergic exposure and dementia, while few studies have included mild cognitive impairment $(\mathrm{MCl})$ as an outcome. $\mathrm{MCl}$ is a potentially reversible stage of cognitive decline between normal cognition and dementia. ${ }^{28}$ Two observational studies report relationships between anticholinergics and $\mathrm{MCl}^{21,22}$ however no prior studies have used dispensing data to evaluate the relationship between anticholinergic exposure and transitions between normal and impaired cognition.

Understanding the transition between cognitive states may improve our understanding of the reversibility of the adverse cognitive effects of anticholinergics. One randomized trial found no

This article is protected by copyright. All rights reserved. 
difference in a memory test in a nursing home population after reducing anticholinergic exposure by $50 \%$ over 8 weeks; ${ }^{29}$ however, the authors report improvement in a small group who discontinued all anticholinergics. Epidemiologic studies suggest that interventions to reduce anticholinergic use would have a more significant impact on populations with mild or no cognitive impairment as a preventative intervention. $^{30}$

To address the question of reversibility, we conducted a secondary data analysis to model the reversibility of the adverse cognitive effects of anticholinergics by merging data from a longitudinal study in older adults in primary care containing multiple cognitive assessments with prescription dispensing records. Our hypothesis was that anticholinergic exposure would increase the transition from normal cognition to mild cognitive impairment and decrease the transition from mild cognitive impairment to normal cognition.

\section{Methods}

Study Population

This prospective observational study was conducted in older adults receiving primary care from Eskenazi Health (formerly known as Wishard Health) in Indianapolis, IN. Eskenazi Health is a large safety net health care system and is responsible for the care of the indigent, uninsured, or under-insured population in Indianapolis. Primary care was provided through nine primary care centers located throughout the city. Potentially eligible patients were screened if they were age 65 years or older, had more than 2 primary care visits in the prior 12 months with a future visit scheduled, and no medical record diagnosis of dementia. Potentially eligible primary care patients were screened with the Mini Mental Status Exam (MMSE) or the Telephone Interview for Cognitive Status (TICS). Patients scoring 14

This article is protected by copyright. All rights reserved. 
or greater on the MMSE or 22 or greater on the TICS, and who had an informant available, were eligible for enrollment into the diagnostic assessment.

This study was reviewed and approved by the institutional review board of the Indiana University-Purdue University of Indianapolis.

\section{Cognitive Diagnosis}

An expert-based consensus panel adjudicated cognitive diagnoses at each assessment, which included the baseline and re-assessment every 12 months up to 48 months (see Figure 1). Participants completed a self-report of health history, depression by the Geriatric Depression Scale, and cognitive assessment with Wechsler Memory Scale-R Logical Memory, Wechsler Memory Scale-R Visual Reproduction, Consortium to Establish A Registry for Alzheimer's Disease (CERAD) Word List Learning task, Boston Naming, Animal Fluency, Wechsler Adult Intelligence Scale-Revised (WAIS-R) Block Design, and Trail Making Tests A \& B. Informants were asked about the range, onset, and progression of cognitive symptoms, functional status with the Functional Assessment Questionnaire, and psychiatric status with the Neuropsychiatric Inventory. A neurologic and physical exam and medication review completed the medical assessment. The consensus diagnosis conference included geriatric, psychiatric, neurologic, and neuropsychiatric experts along with standard criteria to attribute diagnoses of normal cognitive, $\mathrm{MCl}$, and dementia for each participant at each wave. Participants with a diagnosis of normal cognition or $\mathrm{MCl}$ were included in the study, while those with a diagnosis of dementia were excluded.

\section{Measure of Medication Exposure}

Medication data was retrieved from the Indiana Network for Patient Care (INPC), which captures pharmacy dispensing data from outpatient pharmacies located within the Eskenazi Health network as well as dispensed prescriptions from retail pharmacies through Surescripts claims data. ${ }^{31}$ The Pharmacy

This article is protected by copyright. All rights reserved. 
module within the INPC contains dispensed drug name, strength, quantity dispensed, number of days' supplied, and date dispensed for each prescription record. Prescription records were extracted from the 10 years prior to the initial cognitive assessment through to the final cognitive assessment completed by each participant to create two anticholinergic exposure variables used in the analysis. The time-varying exposure variable included anticholinergic prescription records between 12-month cognitive assessments (Figure 1); a historical exposure variable was defined using records for the 10 years of exposure prior to the baseline assessment.

Anticholinergics were defined according to the Anticholinergic Cognitive Burden (ACB) scale, which has been previously validated in similar populations. ${ }^{2,22,27,32,33}$ According to the ACB scale, medications with mild anticholinergic effects were attributed a score of 1 and defined as those with serum anticholinergic activity or in vitro affinity to muscarinic receptors but with no known clinically relevant adverse cognitive effects. Medications with clinically relevant anticholinergic properties were attributed a score of 2 or 3 based on the presence of peripheral anticholinergic side effects only (score of 2) or the presence of both peripheral and central anticholinergic side effects (score of 3).

We defined the total standard daily dose (TSDD) as a cumulative measure of anticholinergic exposure for all anticholinergics identified in the ACB scale (scores 1, 2, and 3) as well as for strong anticholinergics only. When calculating the TSDD, a standard daily dose (SDD) was derived by multiplying the number of medication units (tablets or capsules) dispensed by the strength (milligrams) and then dividing by the minimum effective geriatric dose (MEGD). MEGD was defined by a geriatric medication reference ${ }^{34}$ which has been previously used for similar adjustments. ${ }^{23,35}$ The SDD for all anticholinergics also included a multiplier to weight each drug as defined in the ACB scale (score of 1,2 , or 3 ). For analyses using the SDD from strong anticholinergics only (score $2 \& 3$ ), no weighting was applied. Figure 2 shows that the time-varying anticholinergic exposure variable was defined as a cumulative total SDD (TSDD) by summing each of the SDDs for anticholinergic prescriptions for each subject. TSDD for the

This article is protected by copyright. All rights reserved. 
time-varying anticholinergic exposure variable was further adjusted to accommodate clinical interpretation by dividing TSDD for all ACB medications by 2000 and TSDD for strong anticholinergics by 365.

\section{Demographics and Other Variables}

Demographics and comorbidities were collected through a combination of participant self-report and medical record review of diagnoses. Hypertension was defined as systolic blood pressure greater than $140 \mathrm{mmHg}$ or diastolic blood pressure greater than $90 \mathrm{mmHg}$. Diabetes was defined as glucose greater than $126 \mathrm{mg} / \mathrm{dL}$ fasting or $160 \mathrm{mg} / \mathrm{dL}$ random, or glycosylated hemoglobin A1c greater than 10 . The definition of coronary artery disease included myocardial infarction, angioplasty, coronary artery bypass graft, and stent placement. Congestive heart failure (CHF) included a diagnosis of CHF, cardiomyopathy, or left ventricular hypertrophy. Cancer included history of breast, prostate, lymphoma, colon, or lung cancers.

\section{Statistical Analysis}

T-tests and Fisher's exact tests were used to compare the baseline characteristics between participants with normal cognition and $\mathrm{MCl}$ as well as comparisons between those whose diagnosis transitioned and remained stable. We used logistic regression models with generalized estimating equations (GEE) with the outcomes defined as transition in cognitive diagnosis versus stable diagnosis at 12-month intervals. Transition from $\mathrm{MCl}$ to normal was compared with stable $\mathrm{MCl}$; transition from normal to $\mathrm{MCl}$ was compared with stable normal cognition. Each participant could contribute up to four repeated transitional outcomes for each 12-month segment depending on the duration of participation in the study and the repeated outcomes from the same individuals were adjusted using the GEE approach. Anticholinergic exposure variables were independent variables in each model and were collected during

This article is protected by copyright. All rights reserved. 
the 12-month period between diagnoses as time-dependent variables. A historical anticholinergic exposure variable was also defined using prescription records from the 10 years prior to the baseline cognitive assessment. Because prior studies suggest that only highest exposure over time adversely affects cognition, ${ }^{23}$ we defined historical anticholinergic exposure as a categorical variable of the highest tertile of anticholinergic exposure. Adjusted models included age, race, gender, education, stroke, CHF, and historical anticholinergic medication exposure. Covariates not included in the models were not significantly related to the model outcomes.

Missing dispensed amount fields occurred in 33\% of all anticholinergic records; we addressed missing dispensed amount fields by substituting number of days supplied if available, or 60 days as the most common number of days supplied among all prescription records. Missing prescription strength fields occurred in $21 \%$ of all anticholinergic records and was addressed by substituting minimum effective geriatric doses. A sensitivity analysis excluding missing records was also conducted.

\section{Results}

Among 350 participants, the mean age at baseline was $71.2( \pm 5.1)$ years, $79.1 \%$ were female and $62.0 \%$ were African-American (Table 1). Those diagnosed with $\mathrm{MCl}$ at baseline were more likely to be nonAfrican-American, have lower education, have more comorbidity, and have used any anticholinergic than those diagnosed as cognitively normal. Mean follow up was 3.2 years (standard deviation 0.8 years, range 0.9-4.3 years).

A total of 978 consecutive diagnostic assessments were completed among 350 participants: 229 (22.7\%) with initial $\mathrm{MCl}$ diagnoses remained as $\mathrm{MCl}$ at the subsequent evaluations; 135 (13.8\%) with initial $\mathrm{MCl}$ diagnoses reverted to normal cognition; 7 (0.7\%) with $\mathrm{MCl}$ that transitioned to dementia; 511 (52.2\%) with initial normal cognition that remained normal at the subsequent evaluation; and 103

This article is protected by copyright. All rights reserved. 
(10.5\%) with normal cognition that transitioned to $\mathrm{MCl}$. For the purpose of this analysis, the seven transitions from $\mathrm{MCl}$ to dementia ( $0.7 \%$ of all transitions) were included in the stable $\mathrm{MCl}$ group. Table 2 presents demographic and clinical characteristics between those who transitioned in cognitive diagnosis and those that remained stable stratified by initial diagnosis.

Among the total study population, $70.6 \%$ were exposed to any ACB medication at baseline and $30.6 \%$ were exposed to at least one strong $A C B$, with higher exposure in those diagnosed with $\mathrm{MCl}$ (Table 1). Table 3 presents the anticholinergics used in any period after the baseline assessment. Among participants with an initial diagnosis of normal cognition, use of strong anticholinergics as measured by the TSDD significantly increased the likelihood of transition from normal cognition to $\mathrm{MCl}$ compared with stable normal cognition after adjusting for age, gender, race, education, stroke, $\mathrm{CHF}$, and high prior exposure to strong anticholinergics (odds ratio [OR] 1.15; 95\% confidence interval [Cl]: 1.01-1.31; $p=0.0342$ ) (Table 4). Age also significantly increased the transition from normal cognition to $\mathrm{MCl}(\mathrm{OR} 1.07,95 \% \mathrm{Cl} 1.01-1.12 ; \mathrm{p}=0.0117)$; whereas education reduced the likelihood of transition from normal cognition to $\mathrm{MCl}(\mathrm{OR} 0.78,95 \% \mathrm{Cl} 0.69-0.88), \mathrm{p}<0.001)$. All other covariates, including stroke, gender, race, $\mathrm{CHF}$, and high 10-year exposure to strong anticholinergics did not influence the transition from normal cognition to $\mathrm{MCl}$. Apolipoprotein $\mathrm{E}$ (APOE) e4 did not significantly influence the results, however when included in the model with TSDD of strong anticholinergics as the independent variable and transition from normal cognition to $\mathrm{MCl}$ as the dependent variable, the OR was 1.13 with a $95 \% \mathrm{Cl}$ of $1.00-1.28(\mathrm{p}=0.0573)$. Notably, the TSDD of all anticholinergics was not significantly associated with the transition from normal cognition to $\mathrm{MCl}$. A sensitivity analysis excluding missing data for days' supply and strength from pharmacy fields also showed a significant relationship between increasing exposure to strong anticholinergics and transition from normal cognition to $\mathrm{MCl}(O R$ 1.17, 95\% $\mathrm{Cl} 1.01$ 1.34; $p=0.0304)$.

This article is protected by copyright. All rights reserved. 
Among participants with a diagnosis of $\mathrm{MCl}$, the odds ratio estimates for the reversion to normal cognition were less than one for both measures of anticholinergic exposure suggesting a decreased likelihood of reversion from $\mathrm{MCl}$ to normal among anticholinergic users. However, the relationship was not statistically significant. A history of stroke and being male significantly reduced the likelihood of reversion from $\mathrm{MCl}$ to normal cognition (OR for stroke: $0.43,95 \% \mathrm{Cl}$ 0.23-0.81, $\mathrm{p}=0.0088$; OR for male: $0.51,95 \% \mathrm{Cl} 0.28-0.94 ; \mathrm{p}=0.0310)$.

\section{Discussion}

This analysis provides further evidence of the adverse cognitive effects of anticholinergics by showing higher odds of cognitive decline in community-dwelling older adults without dementia. Specifically, we demonstrate that cumulative exposure to strong anticholinergics, as defined by the TSDD, increased the odds of transitioning from normal cognition to $\mathrm{MCl}$; whereas cumulative exposure to strong anticholinergics did not significantly influence the reversion from $\mathrm{MCl}$ to normal cognition. Our results show a $15 \%$ higher odds of transitioning from normal cognition to $\mathrm{MCl}$ among those using a minimally effective dose of a strong anticholinergic every day for one year, such as paroxetine 10 milligrams once daily. Increasing the dose or adding low-dose anticholinergics multiplied the odds - a $20 \mathrm{mg}$ dose of paroxetine daily for one year resulted in $30 \%$ higher odds of transitioning to $\mathrm{MCl}$.

A recent study described a higher odds of dementia among the highest users of strong anticholinergics over 10 years when using the TSDD to quantify cumulative anticholinergic exposure. ${ }^{23}$ We also recently reported an increasing odds of dementia and $\mathrm{MCl}$ with cumulative anticholinergic exposure based on $\mathrm{ACB}$ score and duration of use. ${ }^{27}$ Other studies using anticholinergic drug scales to calculate exposure have employed categorical variables (exposed vs. unexposed) and sum of ACB scores

This article is protected by copyright. All rights reserved. 
$(0,1,2$, or 3$)$. Our results support the biological gradient (cumulative exposure) condition of causality in epidemiologic studies ${ }^{36}$ for the relationship between strong anticholinergics and $\mathrm{MCl}$.

The hypothesis that anticholinergics increase beta-amyloid and tau proteins to worsen cognition is supported by the findings of higher odds of transition from normal cognition to $\mathrm{MCl}$. This hypothesis would also suggest it is unlikely that de-prescribing (or discontinuing) anticholinergics among current users would be expected to immediately improve cognition. Our results failed to show a statistically significant reduction in the odds of reversion from $\mathrm{MCl}$ to normal cognition with increasing exposure to anticholinergics, with one explanation being that the cholinergic pathway has little influence on cognition among older adults in primary care with a diagnosis of $\mathrm{MCl}$. Another explanation from this analysis suggests other factors such as stroke and gender are more likely to influence this transition. To date, no study has demonstrated a reversible effect on cognition by de-prescribing anticholinergics; however, this area of research has not been widely pursued. Only one prospective intervention reducing anticholinergic burden has been published, and showed that despite a $50 \%$ reduction in anticholinergic drug score, no improvement in memory or global cognition was reported after 8 weeks. ${ }^{29}$ Nearly $70 \%$ of participants in the study had at least mild dementia at baseline, and the target for anticholinergic reduction was not restricted to strong anticholinergics. Despite this, the authors reported an improvement in memory scores among a sub-group $(n=5)$ who discontinued all anticholinergics. Beyond this study, no de-prescribing interventions have been conducted in older adults with $\mathrm{MCl}$ or in a primary care population at risk of cognitive impairment. De-prescribing interventions are needed to determine whether anticholinergic exposure is permanent or reversible.

Opportunities to prevent or delay dementia can have a significant impact on medical, social, and financial outcomes. ${ }^{37}$ Delaying the onset of dementia by one year is projected to prevent 9.2 million cases of dementia by $2050 .{ }^{38}$ Therefore, interventions focused on improving cognition or preventing decline are of great interest in the National Alzheimer's Project Act. ${ }^{39}$

This article is protected by copyright. All rights reserved. 
Strengths of this analysis are the objective measures of medication data and consensus-based diagnosis as the outcome. However, some limitations to the study should be noted. First, use of pharmacy dispensing and claims data does not include use of non-prescription (over-the-counter [OTC]) anticholinergics, such as diphenhydramine and chlorpheniramine. Participants in this study were incentivized to use Eskenazi pharmacies, which recorded use of OTC medications in the dispensing database and improved but not assured the capture of OTC medications. Second, use of pharmacy dispensing and claims data as a measure of exposure assumes medications are consumed by participants. Third, unmeasured variables or severity of disease may have influenced our results, a potential source of bias in any observational study. We were, however, able to merge self-report with medical records to capture the presence or absence of diseases that are important in cognitive evaluation including depression, heart disease, and stroke. However, we note the lack of specific diagnoses such as incontinence and insomnia, which have been associated with dementia in this analysis and therefore cannot rule out indication bias. Lastly, the limited sample size prevented other approaches to modelling reversibility of anticholinergic adverse effects, such as comparing diagnostic transitions among stoppers and starters of strong anticholinergics. Thus, replication of our analysis in larger and more diverse populations would be of interest.

\section{Conclusions}

Our results demonstrate that cumulative exposure to strong anticholinergics increased the transition from normal cognition to $\mathrm{MCl}$ in community-dwelling older adults without dementia. Strong anticholinergics did not have a statistically significant influence on the reversion from $\mathrm{MCl}$ to normal cognition. Interventions preventing or de-prescribing anticholinergic use in community-dwelling older

This article is protected by copyright. All rights reserved. 
adults without dementia should be tested for potential impact on safety, as well as the ability to prevent or delay the onset of cognitive impairment.

\section{Acknowledgments}

Study concept, acquisition of data, conduct of the collection, management, and analysis of the study data, and interpretation of the results were conducted by all authors. Preparation of the manuscript was conducted by Dr. Campbell and Ms. Lane, with revisions and approval performed by Drs. Campbell, Gao, Unverzagt and Ms. Lane. Dr. Campbell and Ms. Lane had full access to the data in the study and take responsibility for the integrity and the accuracy of the data analysis.

\section{References}

1. Castelino RL, Hilmer SN, Bajorek BV, Nishtala P, Chen TF. Drug Burden Index and potentially inappropriate medications in community-dwelling older people: the impact of Home Medicines Review. Drugs Aging 2010;27:135-48.

2. Campbell NL, Boustani MA, Lane KA, et al. Use of anticholinergics and the risk of cognitive impairment in an African American population. Neurology 2010;75:152-9.

3. Society AG. Updated Beers Criteria for potentially inappropriate medication use in older adults. J Am Geriatr Soc 2015;63:2227-2246.

4. CMS. CMS Manual System [online]. Available at: http://www.cms.gov/Regulations-andGuidance/Guidance/Transmittals/downloads/r19soma.pdf. Accessed February 26, 2018.

5. Felton M, Hanlon JT, Perera S, Thorpe JM, Marcum ZA. Racial differences in anticholinergic use among community-dwelling elders. Consult Pharm 2015;30:240-5.

6. Sumukadas D, McMurdo ME, Mangoni AA, Guthrie B. Temporal trends in anticholinergic medication prescription in older people: repeated cross-sectional analysis of population prescribing data. Age Ageing 2014;43:515-21.

7. Mesulam M-M, Guillozet A, Shaw P, Levey A, Duysen E, Lockridge O. Acetylcholinesterase knockouts establish central cholinergic pathways and can use butyrylcholinesterase to hydrolyze acetylcholine. Neuroscience 2002;110:627-39.

8. Everitt BJ, Robbins TW. Central cholinergic systems and cognition. Annu Rev Psychol 1997;48:649-84.

9. Scheiderer $\mathrm{CL}$, McCutchen $\mathrm{E}$, Thacker $\mathrm{EE}$, et al. Sympathetic sprouting drives hippocampal cholinergic reinnervation that prevents loss of a muscarinic receptor-dependent long-term depression at CA3-CA1 synapses. J Neurosci 2006;26:3745-56.

This article is protected by copyright. All rights reserved. 
10. Perry EK, Kilford L, Lees AJ, Burn DJ, Perry RH. Increased Alzheimer pathology in Parkinson's disease related to antimuscarinic drugs. Ann Neurol 2003;54:235-8.

11. del Pino J, Zeballos G, Anadón MJ, et al. Cadmium-induced cell death of basal forebrain cholinergic neurons mediated by muscarinic $M 1$ receptor blockade, increase in GSK-3 $\beta$ enzyme, $\beta$ amyloid and tau protein levels. Arch Toxicol 2016;90:1081-92.

12. Billings LM, Oddo S, Green KN, McGaugh JL, LaFerla FM. Intraneuronal A $\beta$ causes the onset of early Alzheimer's disease-related cognitive deficits in transgenic mice. Neuron 2005;45:675-88.

13. Caccamo A, Oddo S, Billings LM, et al. M1 receptors play a central role in modulating AD-like pathology in transgenic mice. Neuron 2006;49:671-82.

14. Oddo S, Caccamo A, Shepherd JD, et al. Triple-transgenic model of Alzheimer's disease with plaques and tangles: intracellular $A \beta$ and synaptic dysfunction. Neuron 2003;39:409-21.

15. Geula C. Abnormalities of neural circuitry in Alzheimer's disease Hippocampus and cortical cholinergic innervation. Neurology 1998;51:S18-29.

16. Sivaprakasam K. Towards a unifying hypothesis of Alzheimer's disease: cholinergic system linked to plaques, tangles and neuroinflammation. Curr Med Chem 2006;13:2179-88.

17. Bierer LM, Haroutunian V, Gabriel S, et al. Neurochemical correlates of dementia severity in Alzheimer's disease: relative importance of the cholinergic deficits. J Neurochem 1995;64:749-60.

18. Risacher SL, McDonald BC, Tallman EF, et al. Association between anticholinergic medication use and cognition, brain metabolism, and brain atrophy in cognitively normal older adults. JAMA Neurol 2016;73:721-32.

19. Fox C, Smith T, Maidment I, et al. Effect of medications with anti-cholinergic properties on cognitive function, delirium, physical function and mortality: a systematic review. Age Ageing 2014;43:604-15.

20. Fox C, Richardson K, Maidment ID, et al. Anticholinergic medication use and cognitive impairment in the older population: the medical research council cognitive function and ageing study. $J$ Am Geriatr Soc 2011;59:1477-83.

21. Ancelin ML, Artero S, Portet F, Dupuy AM, Touchon J, Ritchie K. Non-degenerative mild cognitive impairment in elderly people and use of anticholinergic drugs: longitudinal cohort study. BMJ 2006;332:455-9.

22. Cai X, Campbell N, Khan B, Callahan C, Boustani M. Long-term anticholinergic use and the aging brain. AlzheimersDement 2013;9:377-85.

23. Gray SL, Anderson ML, Dublin S, et al. Cumulative use of strong anticholinergics and incident dementia: a prospective cohort study. JAMA Intern Med 2015;175:401-7.

24. Sittironnarit $\mathrm{G}$, Ames D, Bush Al, et al. Effects of anticholinergic drugs on cognitive function in older Australians: results from the AIBL study. Dement Geriatr Cogn Disord 2011;31:173-8.

25. Nishtala PS, Narayan SW, Wang T, Hilmer SN. Associations of drug burden index with falls, general practitioner visits, and mortality in older people. Pharmacoepidemiol Drug Saf 2014;23:753-8.

26. Bottiggi KA, Salazar JC, Yu L, et al. Long-term cognitive impact of anticholinergic medications in older adults. Am J Geriatr Psychiatry 2006;14:980-4.

27. Campbell NL, Perkins AJ, Bradt P, et al. Association of anticholinergic burden with cognitive impairment and health care utilization among a diverse ambulatory older adult population.

Pharmacotherapy 2016;36:1123-31.

28. Gao S, Unverzagt FW, Hall KS, et al. Cognitive impairment, incidence, progression, and reversion: findings from a community-based cohort of elderly African Americans. Am J Geriatr Psychiatry 2014;22:670-81.

29. Kersten H, Molden E, Tolo IK, Skovlund E, Engedal K, Wyller TB. Cognitive effects of reducing anticholinergic drug burden in a frail elderly population: a randomized controlled trial. J Gerontol A Biol Sci Med Sci 2013;68:271-8.

This article is protected by copyright. All rights reserved. 
30. Fox C, Livingston G, Maidment ID, et al. The impact of anticholinergic burden in Alzheimer's dementia - the LASER-AD study. Age Ageing 2011;40:730-5.

31. McDonald CJ, Overhage JM, Tierney WM, et al. The Regenstrief Medical Record System: a quarter century experience. Int J Med Inform 1999;54:225-53.

32. Boustani M CN, Munger S, Maidment I, Fox C. The impact of anticholinergics on the aging brain: a review and practical application. Aging Health 2008;4:311-20.

33. Campbell NL, Maidment I, Fox C, Khan BA, Boustani MA. The 2012 Update to the Anticholinergic Cognitive Burden Scale. J Am Geriatr Soc 2013;61:S142-3.

34. Semla TP, Beizer JL, Higbee MD. Geriatric Dosage Handbook, 21s ed. Hudson, OH: Lexicomp; 2016.

35. Gray SL, Dublin S, Yu O, et al. Benzodiazepine use and risk of incident dementia or cognitive decline: prospective population based study. BMJ 2016;352:i90.

36. Hill AB. The environment and disease: association or causation? Proc R Soc Med 1965;58:295300.

37. 2016 Alzheimer's Disease Facts and Figures. Alzheimer Dement 2016;12.

38. Brookmeyer R, Johnson E, Ziegler-Graham K, Arrighi HM. Forecasting the global burden of Alzheimer's disease. Alzheimer Dement 2007;3:186-91.

39. National Plan to Address Alzheimer's Disease: 2016 Update: US Department of Health and Human Services, 2016.

Figure 1. Timeline for collection of cognitive outcome and exposure variables.

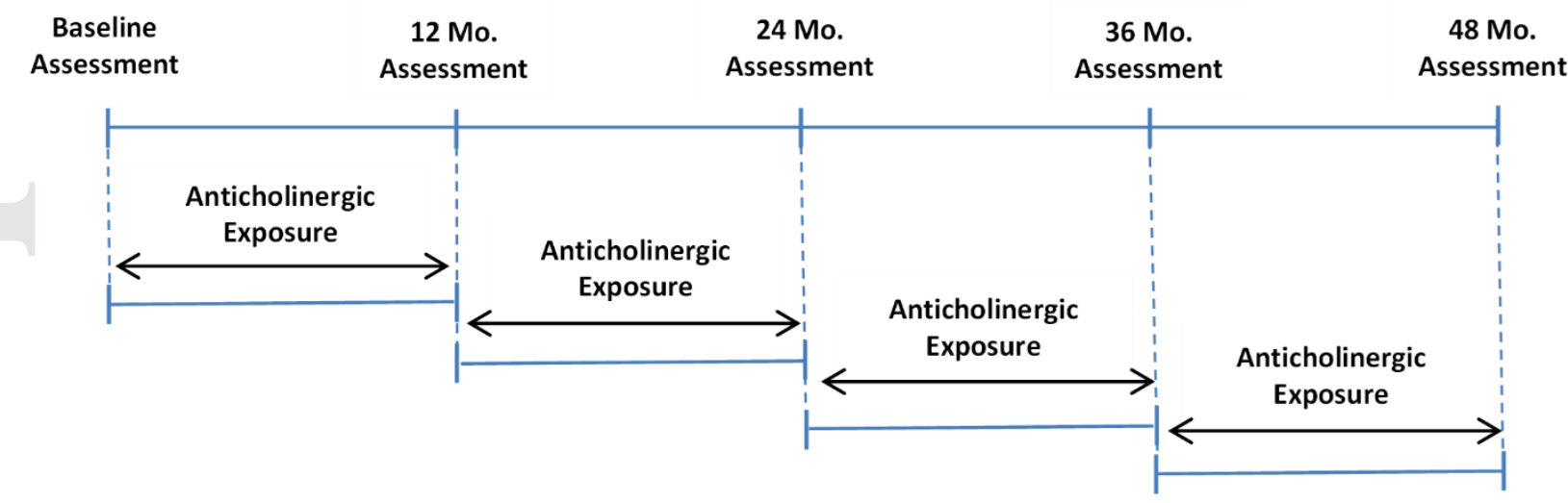

This article is protected by copyright. All rights reserved. 
Figure 2: Calculation of Total Standard Daily Dose for strong anticholinergic exposure

$$
T S D D=\sum_{i} \frac{\text { Drug i dose } \times \# \text { units dispensed }}{\text { Minimum Effective Geriatric Dose }}
$$

*Anticholinergic exposure using all anticholinergics (mild, possible, and strong with scores 1, 2, and 3, respectively) included a multiplier corresponding to the score for each medication in the numerator

This article is protected by copyright. All rights reserved. 
Table 1. Baseline Demographic Characteristics of Study Population

\begin{tabular}{|c|c|c|c|c|}
\hline & $\begin{array}{l}\text { All participants } \\
\mathrm{N}=\mathbf{3 5 0}\end{array}$ & $\begin{array}{l}\text { Normal } \\
\text { cognition } \\
\mathrm{N}=206\end{array}$ & $\begin{array}{l}\mathrm{MCl} \\
\mathrm{N}=144\end{array}$ & p value ${ }^{a}$ \\
\hline Age, mean (SD) & $71.2(5.1)$ & $71.3(5.0)$ & $71.2(5.2)$ & 0.8304 \\
\hline $\begin{array}{l}\text { Race, } \mathrm{n}(\%) \\
\text { African-American } \\
\text { Non-African-American }^{\mathrm{b}}\end{array}$ & $\begin{array}{l}217(62.0) \\
133(38.0)\end{array}$ & $\begin{array}{l}149(72.3) \\
57(27.7)\end{array}$ & $\begin{array}{l}68(47.2) \\
76(52.8)\end{array}$ & $<0.0001$ \\
\hline Female, n (\%) & $277(79.1)$ & $168(81.6)$ & $109(75.7)$ & 0.2288 \\
\hline $\begin{array}{l}\text { Years of Education, mean } \\
\text { (SD) }\end{array}$ & $11.6(2.2)$ & $11.9(2.0)$ & $11.2(2.4)$ & 0.0023 \\
\hline APOE e4 carrier, $n(\%)^{c}$ & $101(29.7)$ & $64(32.2)$ & $37(26.2)$ & 0.2786 \\
\hline Stroke/TIA, n (\%) & $58(16.6)$ & $25(12.1)$ & $33(22.9)$ & 0.0087 \\
\hline CAD, n (\%) & 55 (15.7) & $26(12.6)$ & $29(20.1)$ & 0.0728 \\
\hline CHF, n (\%) & 69 (19.7) & $27(13.1)$ & $42(29.2)$ & 0.0003 \\
\hline Hypertension, n (\%) & $308(88.0)$ & $177(85.9)$ & $131(91.0)$ & 0.1821 \\
\hline Diabetes, n (\%) & $166(47.6)$ & $92(44.7)$ & $74(51.7)$ & 0.2306 \\
\hline Cancer, n (\%) & $64(18.3)$ & $38(18.4)$ & $26(18.1)$ & 1.0000 \\
\hline Depression, n (\%) & $112(32.0)$ & $53(25.7)$ & $59(41.0)$ & 0.0035 \\
\hline $\begin{array}{l}\text { Number of non-ACB meds, } \\
\text { mean (SD) }\end{array}$ & $5.2(3.6)$ & $5.0(3.5)$ & $5.5(3.7)$ & 0.1928 \\
\hline $\begin{array}{l}\text { Any ACB } 1 \text { yr prior to } \\
\text { baseline, } \mathrm{n}(\%)\end{array}$ & $247(70.6)$ & $135(65.5)$ & $112(77.8)$ & 0.0169 \\
\hline $\begin{array}{l}\text { TSDD Any ACB } 10 \text { yrs prior, } \\
\text { mean (SD) }\end{array}$ & 6466 (9103) & 5388 (7969) & $8007(10,350)$ & 0.0113 \\
\hline $\begin{array}{l}\text { Strong ACB } 1 \text { yr prior to } \\
\text { baseline, } \mathrm{n}(\%)\end{array}$ & 107 (30.6\%) & $51(24.8 \%)$ & $56(38.9 \%)$ & 0.0066 \\
\hline $\begin{array}{l}\text { TSDD strong ACB } 10 \text { yrs prior, } \\
\text { mean (SD) }\end{array}$ & $908(2601)$ & 647 (2165) & 1279 (3091) & 0.0355 \\
\hline
\end{tabular}

Cancer (non-skin): breast, prostate, lymphoma, colon, or lung.

This article is protected by copyright. All rights reserved. 
Disease states identified by ICD-9 codes, chart review, or patient report of diagnosis.

$\mathrm{ACB}=$ anticholinergic cognitive burden; $\mathrm{APOE}=$ apolipoprotein $\mathrm{E} ; \mathrm{CAD}=$ coronary artery disease (defined as history of:

myocardial infarction, angioplasty, coronary artery bypass grafting, stent); $\mathrm{CHF}=$ congestive heart failure (defined as history of: $\mathrm{CHF}$, cardiomyopathy, left ventricular hypertrophy); $\mathrm{MCl}=$ mild cognitive impairment, not dementia; $\mathrm{SD}=$ standard deviation; $\mathrm{TIA}=$ transient ischemic attack; TSDD = total standard daily dose.

a $\mathrm{p}$ value for difference between $\mathrm{MCl}$ and normal cognition groups.

${ }^{\mathrm{b}}$ Non-African Americans included 129 Caucasians, 2 biracial, 1 American Indian, and 1 participant indicating 'other' as their race. 'Due to missing data, sample size for APOE e4 is 340 for total population, 199 in normal cognition, and 141 for $\mathrm{MCl}$.

Table 2. Participant Characteristics by Outcomes of Successive Transitions ( $n=$ number of transitions in each group)

\begin{tabular}{|c|c|c|c|c|c|c|}
\hline Initial Diagnosis & Normal & & & $\mathrm{MCl}$ & & \\
\hline Follow-up Diagnosis & $\begin{array}{l}\text { Normal } \\
n=511 *\end{array}$ & $\begin{array}{l}\mathrm{MCl} \\
n=103 *\end{array}$ & p value & $\begin{array}{l}\text { Normal } \\
n=135 *\end{array}$ & $\begin{array}{l}\mathrm{MCl} \\
\mathrm{n}=229 *\end{array}$ & $p$ value \\
\hline Age, mean (SD) & $70.8(4.8)$ & $72.5(4.9)$ & 0.0015 & $70.7(4.3)$ & $72.4(5.7)$ & 0.0044 \\
\hline $\begin{array}{l}\text { Race, } \mathrm{n}(\%) \\
\text { African-American, } \\
\text { Non-African- } \\
\text { American }\end{array}$ & $\begin{array}{l}355(69.5) \\
156(30.5)\end{array}$ & $\begin{array}{l}64(62.1) \\
39(37.9)\end{array}$ & 0.9392 & $\begin{array}{l}67(49.6) \\
68(50.4)\end{array}$ & $\begin{array}{l}126(55.0) \\
103(45.0)\end{array}$ & 0.5486 \\
\hline $\begin{array}{l}\text { Gender, n (\%) } \\
\text { Female }\end{array}$ & $421(82.4)$ & $84(81.6)$ & 0.8498 & $107(79.3)$ & $166(72.5)$ & 0.2493 \\
\hline $\begin{array}{l}\text { Education in years, } \\
\text { mean (SD) }\end{array}$ & $12.2(1.9)$ & $11.1(2.1)$ & $<0.0001$ & $11.3(2.4)$ & $10.9(2.3)$ & 0.1057 \\
\hline $\begin{array}{l}\text { APOE e4 carrier, } n \\
(\%)^{\sim}\end{array}$ & $153(31.0)$ & $33(32.7)$ & 0.6991 & $38(28.6)$ & $73(32.3)$ & 0.5124 \\
\hline Stroke/TIA, n (\%) & $56(11.0)$ & $15(14.6)$ & 0.3203 & $18(13.3)$ & $56(24.5)$ & 0.0100 \\
\hline CAD, $n(\%)$ & $60(11.7)$ & $16(15.5)$ & 0.2715 & $26(19.3)$ & 45 (19.7) & 0.8826 \\
\hline CHF, n (\%) & $71(13.9)$ & $25(24.3)$ & 0.0195 & $39(28.9)$ & $68(29.7)$ & 0.7615 \\
\hline Hypertension, n (\%) & $459(89.8)$ & $92(89.3)$ & 0.8170 & $121(89.6)$ & $197(86.0)$ & 0.2046 \\
\hline Diabetes, n (\%) & $251(49.1)$ & $45(43.7)$ & 0.3062 & $67(49.6)$ & $97(42.4)$ & 0.2229 \\
\hline
\end{tabular}

This article is protected by copyright. All rights reserved. 


\begin{tabular}{|l|l|l|l|l|l|l|}
\hline Cancer, $\mathrm{n}(\%)$ & $110(21.5)$ & $15(14.6)$ & 0.1602 & $22(16.3)$ & $30(13.1)$ & 0.4685 \\
\hline Depression, $\mathrm{n}(\%)$ & $151(29.5)$ & $42(40.8)$ & 0.3951 & $54(40.0)$ & $108(47.2)$ & 0.4583 \\
\hline $\begin{array}{l}\text { Number of non-AC } \\
\text { meds during } \\
\text { transition, Mean (SD) }\end{array}$ & $6.3(3.6)$ & $7.1(3.6)$ & 0.0430 & $6.7(3.9)$ & $6.9(3.8)$ & 0.6989 \\
\hline $\begin{array}{l}\mathrm{N}(\%) \text { exposed to any } \\
\text { ACB in transition }\end{array}$ & $387(75.7)$ & $84(81.6)$ & 0.2965 & $106(78.5)$ & $187(81.7)$ & 0.3710 \\
\hline $\begin{array}{l}\mathrm{N}(\%) \text { exposed to } \\
\text { strong ACB in } \\
\text { transition }\end{array}$ & $150(29.4)$ & $42(40.8)$ & 0.0166 & $51(37.8)$ & $96(41.9)$ & 0.3211 \\
\hline
\end{tabular}

Cancer (non-skin) defined as: breast, prostate, lymphoma, colon, or lung.

Disease states identified by ICD-9 codes, chart review, or patient report of diagnosis.

*sample size defined by number of transitions rather than number of participants.

$A C=$ anticholinergic $A C B=$ anticholinergic cognitive burden; $A P O E=$ apolipoprotein $E ; C A D=$ coronary artery disease (defined as history of: myocardial infarction, angioplasty, coronary artery bypass grafting, stent); $\mathrm{CHF}=$ congestive heart failure (defined as history of: $\mathrm{CHF}$, cardiomyopathy, left ventricular hypertrophy); $\mathrm{MCl}=$ mild cognitive impairment, not dementia; $\mathrm{TIA}=$ transient ischemic attack; SD = standard deviation.

Table 3. Report of Anticholinergic Exposure at Any Wave Following Baseline

\begin{tabular}{|c|c|c|c|c|c|}
\hline ACB Score 1 & $\begin{array}{l}\text { Proportion } \\
\text { Exposed* }\end{array}$ & ACB Score 2 & $\begin{array}{l}\text { Proportion } \\
\text { Exposed* }\end{array}$ & ACB Score 3 & $\begin{array}{l}\text { Proportion } \\
\text { Exposed* }\end{array}$ \\
\hline Alprazolam & $2.0 \%$ & Carbamazepine & $1.4 \%$ & Amitriptyline & $7.4 \%$ \\
\hline Aripiprazole & $0.3 \%$ & Cyclobenzaprine & $12.0 \%$ & Atropine & $0.6 \%$ \\
\hline Atenolol & $10.9 \%$ & Oxcarbazepine & $0.3 \%$ & Chlorcyclyzine & $0.9 \%$ \\
\hline Bupropion & $6.6 \%$ & & & Chlorpheniramine & $0.3 \%$ \\
\hline Captopril & $0.3 \%$ & & & Clemastine & $0.3 \%$ \\
\hline Cetirizine & $2.6 \%$ & & & Dicyclomine & $2.0 \%$ \\
\hline Chlorthalidone & $0.6 \%$ & & & Diphenhydramine & $1.1 \%$ \\
\hline Codeine & $10.6 \%$ & & & $\begin{array}{l}\text { Diphenoxylate- } \\
\text { Atropine }\end{array}$ & $0.6 \%$ \\
\hline Colchicine & $4.3 \%$ & & & Doxepin & $1.1 \%$ \\
\hline
\end{tabular}

This article is protected by copyright. All rights reserved. 


\begin{tabular}{|c|c|c|c|}
\hline Diazepam & $4.0 \%$ & Hydroxyzine & $12.9 \%$ \\
\hline Digoxin & $4.3 \%$ & Meclizine & $8.0 \%$ \\
\hline Fentanyl & $2.6 \%$ & Nortriptyline & $1.7 \%$ \\
\hline Furosemide & $24.6 \%$ & Olanzapine & $0.9 \%$ \\
\hline Haloperidol & $0.3 \%$ & Oxybutynin & $10.0 \%$ \\
\hline Hydralazine & $11.1 \%$ & Paroxetine & $3.1 \%$ \\
\hline Isosorbide & $10.6 \%$ & Promethazine & $7.7 \%$ \\
\hline Levocetirizine & $0.3 \%$ & Propantheline & $0.3 \%$ \\
\hline Loperamide & $1.1 \%$ & Quetiapine & $1.7 \%$ \\
\hline Loratadine & $1.4 \%$ & Scopolamine & $0.3 \%$ \\
\hline Metoprolol & $42.0 \%$ & Solifenacin & $0.3 \%$ \\
\hline Morphine & $3.1 \%$ & Tolterodine & $2.6 \%$ \\
\hline Nifedipine & $0.6 \%$ & Trifluoperazine & $0.3 \%$ \\
\hline Prednisone & $18.3 \%$ & Trihexyphenidyl & $0.3 \%$ \\
\hline Ranitidine & $17.4 \%$ & & \\
\hline Risperidone & $1.7 \%$ & & \\
\hline Theophylline & $1.1 \%$ & & \\
\hline Trazodone & $17.1 \%$ & & \\
\hline $\begin{array}{l}\text { Triamterene- } \\
\text { Hydrochlorothiazide }\end{array}$ & $10.6 \%$ & & \\
\hline Venlafaxine & $1.4 \%$ & & \\
\hline Warfarin & $13.7 \%$ & & \\
\hline
\end{tabular}

$A C B=$ anticholinergic cognitive burden.

* Medication use reported as proportion of all participants who used the medication at any point after baseline. Denominator for the proportion was 350.

This article is protected by copyright. All rights reserved. 
Table 4. Results of Logistic Regression Models of the Transition in Cognitive Diagnosis Compared With Stable Diagnosis

\begin{tabular}{|c|c|c|c|}
\hline Outcomes & Unadjusted odds ratio & $\begin{array}{l}\text { Adjusted odds } \\
\text { ratio }\end{array}$ & $\begin{array}{l}\text { Adjusted } p \\
\text { value }^{a}\end{array}$ \\
\hline \multicolumn{4}{|c|}{ Normal to $\mathrm{MCl}$ vs Normal to Normal } \\
\hline TSDD: All ACB & $1.18(0.99-1.42)$ & $1.12(0.93-1.36)$ & 0.2290 \\
\hline TSDD: Strong ACB & $1.16(1.04-1.29)$ & $1.15(1.01-1.31)$ & 0.0342 \\
\hline \multicolumn{4}{|c|}{$\mathrm{MCl}$ to Normal vs $\mathrm{MCl}$ to $\mathrm{MCl}$} \\
\hline TSDD: All ACB & $0.93(0.82-1.05)$ & $0.92(0.81-1.05)$ & 0.2121 \\
\hline TSDD: Strong ACB & $0.96(0.87-1.06)$ & $0.95(0.86-1.05)$ & 0.3266 \\
\hline
\end{tabular}

$\mathrm{ACB}=$ anticholinergic cognitive burden; $\mathrm{MCl}$ = mild cognitive impairment; TSDD = total standard daily dose.

${ }^{a}$ Adjusted p-value includes: age, gender, race, education, history of stroke, history of congestive heart failure, and highest tertile of 10-year TSDD for strong anticholinergics.

This article is protected by copyright. All rights reserved. 